\title{
Evaluation of the epidemiological and economic consequences of control scenarios for bovine viral diarrhea virus in dairy herds
}

\author{
I. M. G. A. Santman-Berends, ${ }^{1}$ M. H. Mars, L. van Duijn, and G. van Schaik \\ GD Animal Health, PO Box 9, 7400 AA Deventer, the Netherlands
}

\begin{abstract}
Bovine viral diarrhea virus (BVDV) is an important endemic infection. However, no information was available on whether it would be economically beneficial to implement a national control program in the Netherlands. Therefore, a stochastic simulation model was developed in which control scenarios were added to compare the epidemiological and economic consequences of BVDV control in Dutch dairy herds in the next 10 yr. In the epidemiological part of the model, herds could be classified as susceptible, infectious, recovered, or vaccinated. The outputs of the epidemiological module served as input for the economic module. Net costs that could be attributed to bovine viral diarrhea consisted of production losses, costs for testing, and culling persistently infected cattle in the present voluntary Dutch BVDV control program and costs for vaccination. Four different control scenarios were simulated, involving testing and culling of persistently infected (based on serum or ear-notch testing), and monitoring BVDV statuses and vaccination and were derived from BVDV control programs that are currently executed in Europe. The costs and benefits of BVDV control in the current situation and in each of the simulated control scenarios were evaluated assuming an annual discount rate of $2 \%$. The model estimated a mean BVDV herd prevalence of $18.0 \%$ in 2014 and showed a slightly decreasing prevalence over time. The outputs seemed realistic for the present situation in the Netherlands when compared with actual survey data. The average annual net costs associated with bovine viral diarrhea were estimated at $€ 27.8$ million for the dairy industry. Two control scenarios were beneficial in controlling BVDV during the study period (between 2015 and 2025). In the scenario where tracing and removing of PI animals and monitoring of the subsequent status was obligatory, the benefit to cost $(\mathrm{B} / \mathrm{C})$ ratio was 1.5 ( $€ 1.5$ benefit for each invested euro). In the scenario in which the BVDV status of all herds was determined,
\end{abstract}

Received December 18, 2014.

Accepted July 27, 2015.

${ }^{1}$ Corresponding author: i.santman@gdanimalhealth.com followed by voluntary measures before control measures became obligatory, the $\mathrm{B} / \mathrm{C}$ ratio was 1.1 . The $\mathrm{B} / \mathrm{C}$ ratio of the scenarios included could be even higher when it was assumed that nondairy herds participated in the control program as well. The model provided the opportunity to compare the effect of voluntary and mandatory control scenarios on the BVDV prevalence and costs and benefits relative to the current situation in the Netherlands. The model was used to support policy makers in their decisions about a BVDV control program.

Key words: dairy cattle, bovine viral diarrhea virus, control scenario, stochastic model

\section{INTRODUCTION}

Bovine viral diarrhea virus (BVDV) is endemic in many cattle populations throughout Europe. In previous studies, seropositive cattle were found in $47 \%$ to $100 \%$ of the herds in several European countries (Houe, 1999; Rüfenacht et al., 2000; Cowley et al., 2012; Sarrazin et al., 2013). The Netherlands has a voluntary BVDV control program in which herds can obtain a BVDV-free certificate (Mars and Van Maanen, 2005). Nevertheless, in the noncertified herds an indication of virus circulation among young stock, between 8 and 12 mo of age, was present in $13.6 \%$ of the dairy farms in 2014 (Veldhuis et al., 2014). This is a slight underestimation of the total BVDV herd prevalence because these percentages are based on circulation in young stock only. Infections with BVDV can, in transiently infected cows, remain subclinical but can also lead to severe clinical signs (Waage, 2000; Lindberg, 2003; Evermann and Barrington, 2005). In addition, it is known that BVDV leads to immunosuppression, which enhances the probability that cattle are secondarily infected by other pathogens (Potgieter, 1988; Wilhelmsen et al., 1990; Potgieter, 1995). Bovine viral diarrhea virus can be transmitted both horizontally and vertically, where vertical transmission in early pregnancy may result in the birth of persistently infected calves (PI; Van Oirschot, 1983; McGowan et al., 1993; Houe, 1995). Persistently infected cattle are the most important source for spread of the virus and are the main 
reason of maintaining the infection within a herd, because they continuously shed large amounts of virus (Lindberg and Houe, 2005).

The economic losses of a bovine viral diarrhea (BVD) infection depend on the serological status of cattle in a herd, the severity of the symptoms, the duration of infection and the interaction with other pathogens. In different studies the direct costs of a BVD infection in dairy herds varied between $€ 21$ and $€ 135$ per cow but could be as high as €340 per cow when simultaneously other infections occurred or in case of highly virulent strains (Hogeveen et al., 2003; Houe, 2003; Fourichon et al., 2005; Valle et al., 2005; Lindberg et al., 2006). In 2003, the losses of BVDV on national level ranged between $€ 7.5$ million and $€ 30$ million per million calvings (Houe, 2003).

Because of this great economic importance, several European countries decided to implement BVDV eradication programs. At this moment, the Scandinavian countries are free of BVDV (Houe, 2005) and control or eradication programs are in place in Austria, Switzerland, Germany, Ireland, Scotland, France, and parts of Italy (Houe et al., 2006; Meier et al., 2010; Barrett et al., 2011; Presi et al., 2011; Stott et al., 2012; Tavella et al., 2012; Voas, 2012). In the Netherlands, BVD is considered one of the most important endemic diseases. However, there was no information whether or not it would be economically beneficial to implement a national control program. A possibility to determine the costs and benefits of control scenarios, is to develop a between-herd simulation model in which the effect of different control scenarios can be compared with the present development. However, the models that were developed to evaluate transmission and in some cases economic consequences of BVDV infections, explicitly studied within-herd transmission (Pasman et al., 1994; Viet et al., 2004, 2005; Ezanno et al., 2008; Stott et al., 2012). Two studies have been found that evaluated between herd BVDV transmission (Courcoul and Ezanno, 2010; Tinsley et al., 2012). Courcoul and Ezanno (2010) studied the influence of neighboring contacts and animal movements on within and between herd spread of BVDV with 2 coupled stochastic compartmental models. The study of Tinsley et al. (2012) studied the spread between beef herds in Scotland, with a stochastic SIS model based on 2 parameters (i.e., disease transmission probability and farm self-clearance probability). These models were not applicable for the Dutch situation. In our model, we wanted to include the BVDV spread between herds and incorporate time-dependent parameters that influenced the risk of introduction and subsequent clearance from the virus. Examples of time-dependent variables were the proportion of herds participating in the Dutch voluntarily
BVDV control program and the proportion of herds implementing vaccination. Furthermore, we wanted to develop a model in which the costs and benefits of voluntary and mandatory BVDV control measures over time could be evaluated. This was not possible with the earlier described methods that focused exclusively on transmission and did not include economic consequences of BVDV infections. Bergevoet et al. (2009) modeled between herd transmission and the subsequent economic consequences of Salmonella for all dairy herds in the Netherlands, and it was decided to use the same modeling approach for BVDV.

The aim of this study was to compare the epidemiological and economic consequences of several control scenarios for Dutch dairy herds using a stochastic simulation model.

\section{MATERIALS AND METHODS}

The model that was developed to predict the BVDV prevalence and subsequent costs was a stochastic simulation model that was built in MS Excel (Microsoft Corp., Redmond, WA) and @Risk 6.2.0 (Palisade Corporation, Ithaca, NY). The stability of the model outputs were evaluated by comparing the outputs of different numbers of iterations and was determined stable after 5,000 iterations when the mean and variation of the output were stable. Therefore, outputs that are presented in this paper are based on 5,000 iterations. Within the model, 2 separate modules were distinguished. An epidemiological module in which a susceptible (S), infectious (I), recovered $(\mathbf{R})$, or vaccinated (V) stochastic model was used to represent the BVDV incidence risk and prevalence in dairy herds on a monthly basis. The results of the epidemiological module served as input for the economic module in which losses due to infections with BVDV, costs of vaccination and participation in the voluntary BVDV eradication program, and costs of different eradication scenarios were calculated on a yearly basis.

The model inputs were obtained from census data from the identification and registration system $(\mathbf{I} \& \mathbf{R})$, data from the voluntary BVDV control program that is conducted by GD in the Netherlands, including the proportion of participating herds, the number of PI calves detected in herds during the process of certification, the proportion of herds with a new BVDV outbreak, and a BVDV survey that was conducted in 2008 (Bartels et al., 2008). The exact parameters and data sources from which the values of these parameters were derived are presented in Appendix Table A1. The model was validated based on the results of BVDV surveys in the Netherlands in 2010, 2012, and 2014 (Brouwer-Middelesch, 2010, 2012; Veldhuis et al., 
2014). Parameters for which no data were available were estimated based on literature or by means of expert opinion (M. H. Mars, L. van Duijn, A. Moen and K. Verhoeff; GD Animal Health, Deventer the Netherlands). To account for uncertainty in the values of the parameters that were estimated by means of expert opinion, Pert distributions based on most likely values and ranges were included instead of fixed values (Vose, 2008). Outputs represented 2014 until 2025. A more detailed description of the model and its input values is presented below.

\section{Epidemiologic Module}

In the epidemiological module, a state transition model was used that distinguished the 4 different states, S, I, R, and V, for a dairy herd. The definition of the $\mathrm{S}$ status was a dairy herd (all cattle including cows, young stock, and calves) in which no live PI cattle were present, that was not experiencing transmission of BVDV infection and in which at most $50 \%$ of the cattle (including calves and heifers) were seropositive. The herd could be free but could also house cattle pregnant with PI. In the latter case, the herd evolves to the I status after birth of the PI. In an I herd, live PI cattle were present and the infection was not under control. After all PI cattle were removed, because they died, were sold, or were culled, the herd evolves to the $\mathrm{R}$ state. The definition of the $\mathrm{R}$ status was a dairy herd that was once again free from infection because all PI cattle were removed or a herd in which the infection was under control (any newborn PI are detected and removed immediately). In these herds, more than $50 \%$ of the cattle were seropositive. Finally, the V status was defined as a herd that is actively immunized by vaccination and does not suffer from any losses due to BVDV. The probability for a herd to develop from one state to another is presented by a state transition matrix (Table 1). The probability to transfer from state $\mathrm{S}$ to state I (pSI) can be described by means of equation 1 :

$$
\mathrm{pSI}=\mathrm{pE}+\mathrm{pB}
$$

Parameter $\mathrm{pE}$ describes the additional risk in herds with the presence of one or more of the included risk factors and is described by equation 2 :

$$
\mathrm{pE}=\left(1-e^{-\Sigma \beta_{i} \times \operatorname{prev}_{i} \times \mathrm{I} / \mathrm{N}}\right),
$$

where $\beta_{i}=$ the amount of risk for each risk factor $i$, $\operatorname{prev}_{i}=$ the prevalence of risk factor $i$ in Dutch dairy herds, $\mathrm{I} / \mathrm{N}=$ the proportion of infectious herds, and $i=$ risk factors for BVDV that were included in this study (i.e., purchase, grazing young stock on other properties, and over-the-fence contacts).

The magnitude of risk of each of the risk factors included was obtained from literature (Table 2). When odds ratios were provided, they were transformed into relative risks using the method described by Beaudeau and Fourichon (1998).

The prevalence of the risk factors in Dutch dairy farms was calculated using I\&R census data. From these data, it appeared that in $48 \%$ of the dairy herds, cattle were purchased during a year. In total, $4 \%$ of the herds appeared to raise their young stock at other cattle farms, and in $9 \%$ of the herds, in theory, cattle had the possibility to have over-the-fence contacts with cattle from other farms because they were located next to another dairy farm.

Parameter $\mathrm{pB}$ represents the probability that a dairy herd is infected without the presence of one of the known risk factors. This probability is the result of the total BVDV incidence risk in the dairy cow population minus the incidence risk that can be attributed to one of the known risk factors [i.e., purchase of cows, over-the-fence contacts, and grazing young stock on other pastures (Table 2)]. The yearly incidence risk of BVDV was derived from data concerning new BVDV infections in Dutch dairy farms that participated in the voluntary BVDV control program, divided by all Dutch dairy herds participating in this program in a specific year. Nevertheless, these farms may be less likely to become infected because more biosecurity measures may be taken in these herds to prevent incursion of the virus, for example, testing purchased cattle for

Table 1. The state-transition matrix used to study the epidemiological and economic consequences of various control scenarios for bovine viral diarrhea virus (BVDV) infections in Dutch dairy herds ${ }^{1}$

\begin{tabular}{lllll}
\hline & \multicolumn{3}{c}{ To: } \\
\cline { 2 - 5 } From: & $\mathrm{S}$ & $\mathrm{I}$ & $\mathrm{R}$ & $\mathrm{V}$ \\
\hline $\mathrm{S}$ & $1-(\mathrm{pSI}+\mathrm{pSV})$ & $\mathrm{pSI}$ & 0 & $\mathrm{pSV}$ \\
$\mathrm{I}$ & $\mathrm{pIS}$ & $1-(\mathrm{pIR}+\mathrm{pIS}+\mathrm{pIV})$ & $\mathrm{pIR}$ & $\mathrm{pIV}$ \\
$\mathrm{R}$ & $\mathrm{pRS}$ & 0 & $1-(\mathrm{pRS}+\mathrm{pRV})$ & $\mathrm{pRV}$ \\
$\mathrm{V}$ & $\mathrm{pVS}$ & $\mathrm{pVI}$ & $\mathrm{pVR}$ & $\mathrm{pV}$ \\
\hline${ }^{1} \mathrm{~S}=$ susceptible; $\mathrm{I}=$ infectious; $\mathrm{R}=$ recovered; $\mathrm{V}=$ vaccinated. & &
\end{tabular}


Table 2. Risk factors associated with the introduction of bovine viral diarrhea virus (BVDV) in Dutch dairy herds that were included in the model aiming at evaluating epidemiological and economic consequences of various control scenarios for BVDV infections between 2015 and 2025

\begin{tabular}{|c|c|c|c|c|c|c|c|}
\hline & \multirow[b]{2}{*}{ Risk factor } & \multirow[b]{2}{*}{ Reference } & \multicolumn{2}{|c|}{ Yearly incidence risk ${ }^{1}(\%)$} & \multirow[b]{2}{*}{$\mathrm{OR}^{2}$} & \multirow[b]{2}{*}{$\mathrm{RR}^{3}$} & \multirow[b]{2}{*}{ Beta } \\
\hline & & & $\begin{array}{c}\text { Certified } \\
\text { BVDV-free } \\
\text { herds }\end{array}$ & $\begin{array}{c}\text { Herds with } \\
\text { unknown } \\
\text { BVDV } \\
\text { status }\end{array}$ & & & \\
\hline$\overline{\mathrm{pE}^{4}}$ & Purchase & $\begin{array}{l}\text { Valle et al., 1999; Presi et al., } \\
2011\end{array}$ & 37 & 51 & 1.8 & 1.35 & 0.30 \\
\hline
\end{tabular}

${ }^{1}$ Based on identification and registration data.

${ }^{2} \mathrm{OR}=$ odds ratio.

${ }^{3} \mathrm{RR}=$ relative risk.

${ }^{4}$ Risk attributable to known risk factors.

BVDV. The experts assumed that the incidence risk of BVDV in these herds was the minimum incidence risk of BVDV on herd level in the Netherlands and that most likely the real incidence risk was 1.5 times higher. The maximum was estimated to be 3 times higher than the minimum value. Therefore, the BVDV incidence risk was included in the model by means of a PERT distribution with minimum 0.08 , most likely 0.12 , and maximum 0.23 .

In the model, it was assumed that $90 \%$ of $\mathrm{pB}$ was attributed to dairy herds $\left(\mathrm{pB}_{\text {dairy }}\right)$ and that the remaining $10 \%$ of $\mathrm{pB}$ was associated with nondairy herds ( $\mathrm{pB}_{\text {nondairy }}$; i.e., suckling cow holders, beef, veal, and small-scale cattle farmers). This $10 \%$ risk from nondairy farms is an assumption that was determined in consultation with the experts. The $10 \%$ risk was considered a worst-case scenario, given that the prevalence in nondairy herds is comparable with the prevalence in dairy herds and that the amount of contacts between dairy and nondairy farms in the Netherlands is limited. Given the arbitrary division of $\mathrm{pB}$ for dairy and nondairy, a sensitivity analysis was carried out to evaluate the effect of this assumption on the outputs of the model. Parameter $\mathrm{pB}$ is described with equation 3 :

$$
\mathrm{pB}=90 \% \times \mathrm{pB} \times \mathrm{I}_{\text {dairy }}+10 \% \times \mathrm{pB} \times \mathrm{I}_{\text {nondairy }} .
$$

The probability to return from state I to state $\mathrm{S}$ was depending on possible actions taken by the farmer at the moment a PI calf was born. When a PI calf is introduced in the herd by means of birth, it is assumed that in $50 \%$ of these cases this calf is male and will be removed from the herd within $14 \mathrm{~d}$ after birth. These calves do not have the opportunity to infect many cows, and therefore it is assumed that after removal of these calves the herd returns to the susceptible state. In addi- tion, a small part of the female PI calves will die before they can infect other cattle in the farm and a part will not be kept for replacement. The experts expected that the birth of $60 \%$ of all PI calves in susceptible herds in the Netherlands will not lead to a major outbreak. Therefore, it was assumed that $60 \%$ of the birth of PI calves will not lead to an I herd and will not lead to losses as a result of a BVDV infection. The probability of returning to state $\mathrm{S}$ after the first PI calf is born can be described by the following equation:

$$
\mathrm{pIS}_{t}=0.6 \times \mathrm{pSI}_{t-1} .
$$

After a herd is infectious because of the presence of a PI animal, the herd can evolve to state R, state V, or can remain in status I. The probability of evolving to the recovered state $\mathrm{R}$ is dependent on the time until all PI are removed from the herd and can be described by the following equation:

$$
\mathrm{pIR}=1-e^{-1 / \delta} .
$$

In this equation, $\delta$ is the average duration of the infectious period in a herd. The duration of the infectious period differed between herds that participated in the voluntary BVDV control program, herds that did not participate in this program but had a known BVDV status, and herds with an unknown BVDV status. Farmers that participated in the voluntary BVDV control program and were certified BVDV free are obliged to evaluate their free status twice a year by submitting blood samples of 5 calves between 8 and 12 mo of age to GD Animal Health to monitor whether virus circulation occurs. These herds were assumed to remain infected for a maximum of 6 mo (median $4 \mathrm{mo}$ ). If virus circulation is indicated during the evaluation of 
the free status, actions are taken to re-establish the BVDV-free status in the herd (Mars and Van Maanen, 2005). These actions involve immediate tracing and culling of all PI cattle and mandatory testing of all newborn calves during the subsequent 10 mo. If a newborn calf appears to be a PI the calf is culled. When no PI calves are detected during a 10-mo period, the herd regains the BVDV-free certificate. In addition, the herds that are not certified BVDV free can either have an unknown BVDV status (approximately 80\% in 2008; source, BVDV control program data) or are monitoring their BVDV status in another way. Thus, a part of these herds will take action when an indication of a new BVDV infection is present. In addition, over time the proportion of herds that participated in the voluntary BVDV control program and herds with a known BVDV status were increasing. In 2008, $15 \%$ of the herds were certified BVDV free. Currently (2014), $25 \%$ of all Dutch dairy herds are certified BVDV free. This increase was included in the model by increasing the participation in the voluntary control program at $1 \%$ per year up to a maximum of $35 \%$ of all herds.

The experts assumed that herds that were not participating in the voluntary BVDV control program, but knew their status, remained infected for a median of 12 mo. In addition, it was assumed that herds with an unknown BVDV status could only obtain clearance of the virus in their herds by coincidence. In a study by Viet et al. (2004), clearance of the virus by coincidence was achieved in $50 \%$ of the herds after a period of $3 \mathrm{yr}$ and 5 mo. Therefore, a duration of 41 mo in the infectious state was assumed for the herds with an unknown BVDV status. Thus, it was assumed that at the start of the model, the average herd (either certified BVDVfree, BVDV known status, or BVDV unknown status) remained in the infectious state for a median period of 30 mo. After reaching $\mathrm{R}$ status, the majority of the cows were seropositive and a major outbreak causing a large amount of losses was assumed impossible until at least $50 \%$ of the cows were seronegative. Evolving from the $\mathrm{R}$ to the $\mathrm{S}$ state depends on a decreasing amount of seropositive cows and is described by equation 6 :

$$
\mathrm{pRS}=1-e^{-1 / \gamma}
$$

where $\gamma$ represents the average duration in which more than $50 \%$ of the seropositive cattle are replaced by seronegative ones. This duration was assumed equal to the duration in which $50 \%$ of the cattle are replaced, which occurs after a median period of 26 mo based on the I\&R data. Depending on the type of housing (calves $(<1 \mathrm{yr}$ old $)$ and young stock (1-2 yr old) together or separate, part of the young stock might remain seronegative, which might shorten the duration in the $\mathrm{R}$ status. On the other hand, herds in which $100 \%$ of the cattle were infected might remain longer in status $R$ because, after 2 yr the calves and young stock will be seronegative but the percentage of seropositive cows (which can potentially produce PI) might be over $50 \%$. To include the variability, this parameter was included as a PERT distribution in the model with a minimum duration of 22 and a maximum duration of 30 mo.

The probability of evolving from state $\mathrm{S}$, I, or $\mathrm{R}$ to state $\mathrm{V}$ is identical and is equal to the proportion of herds that start with vaccination in each month. The pharmaceutical industry estimated that in 2009 approximately $15 \%$ of the dairy farmers vaccinated their cattle for BVDV and that this percentage showed a slight increase over time. Therefore, the value for this parameter was included as a PERT distribution with $10 \%$ as minimum, $15 \%$ as most likely value, and $20 \%$ as maximum (personal communication) and was assumed to increase at $1 \%$ every year up to a maximum of $25 \%$. Vaccination induced immunity could disappear when a farmer decided to stop vaccinating the herd or when the vaccination was not sufficient because (1) the vaccine was not effective in the herd (assumed as a $0.1 \%$ probability) or (2) the herd was not vaccinated properly, on time, or both (assumed as a 10\% probability). Besides including changing vaccination coverage over time, changing participation rates of herds in the voluntary BVDV control program was also incorporated in the model by including a linear increase until an assumed maximum was achieved in the situation of a voluntary program. This assumption was based on previous experience in the field and the general attitude and perception of farmers toward voluntary control programs in the Netherlands. The slope of the increasing value was based on actual developments in census data.

\section{Economics Module}

With the economics module, the net costs (NC) attributable to BVDV in 2014 were calculated and consisted of production losses (PL) caused by BVDV infections and control costs to prevent infection by (1) participating in the voluntary BVDV control program $\left(\mathrm{CC}_{\text {vol_testcul }}\right)$ or by (2) implementing vaccination $\left(\mathrm{CC}_{\mathrm{vacc}}\right.$; equation 7$)$ :

$$
\mathrm{NC}=\left(\mathrm{PL}+\mathrm{CC}_{\mathrm{vol} \_ \text {testcul }}+\mathrm{CC}_{\mathrm{vacc}}\right) .
$$

Multiple papers have studied production losses in dairy and beef cattle, and in general, the direct production 
losses due to BVDV infections appeared to vary between $€ 21$ and €135 per milking cow (Wentink and Dijkhuizen, 1990; Stelwagen and Dijkhuizen, 1998; Hogeveen et al., 2003; Houe, 2003; Fourichon et al., 2005; Valle et al., 2005; Lindberg et al., 2006). The different studies estimated production losses in different countries with different herd sizes and different housing systems. Therefore, the estimates of the production losses from the study of Hogeveen et al. (2003) that was conducted for the Dutch situation were used for our model. In this study, the production losses per milking cow due to BVD were estimated to range from minimum €19 to maximum $€ 384$ per milking cow, with $€ 72$ as the most likely value. The production losses from this study were indexed with $2.5 \%$ per year between the year of publication (2003) and the year of development of the model (2014). In this way, the losses were realistic for the current situation and were comparable with the control costs that were based on prices in 2014. It was assumed that losses because of BVDV infections could only occur when susceptible herds became infected due to purchase of PI cattle or cattle carrying a PI fetus. The $\mathrm{R}$ herds were, by definition, not infected with BVDV and thus had no production losses from BVDV infections.

The costs of BVDV control that were included consist of costs of participation in the voluntary BVDV control program or costs of biannual (twice a year) vaccination of all cows in the herd. Costs of participation in the BVDV control program involved the actions that had to be taken by a farmer to obtain the free status. These actions consist of an initial screening of (1) all milking cows by means of testing the bulk milk and (2) all remaining cattle $>1$ mo old by means of testing serum, for the presence of BVDV. When BVDV was detected in bulk milk, all milking cows were tested individually as well. Subsequently, virus-positive cattle were culled and all newborn calves were tested for presence of virus for a period of 10 mo. When a newborn calf was tested to be a PI, the period in which all newborn calves were tested for presence of BVDV was prolonged another 10 mo. When no PI cattle are detected in this 10-mo period, the herd is certified BVDV free. The average number of PI cattle that is detected during the intake of the program was based on historic results of the voluntary BVDV control program in the Netherlands and was assumed to range between 1 and 8 . The costs that were included consist of sampling costs, laboratory testing costs, and if PI cows were detected, replacement costs of these PI animals (see Appendix Table A1 for the exact parameter estimates). When a herd was certified BVDV-free, the farmer had additional costs for monitoring the free status by biannual antibody testing of young stock ( 5 in the age of 8 to $12 \mathrm{mo}$ ) for detection of virus circulation and costs for preventing (re-)introduction of the virus when purchasing cattle. An overview of the costs is presented in Appendix Table A1. Herd size steadily increased in the last decade, causing increasing costs for control efforts and increasing losses when infections occurred. In addition, the number of dairy herds in the Netherlands decreased in this period. Both the exact increase in herd size and the decrease in number of dairy herds were based on the $I \& R$ data from 2008 until 2014 and it was assumed that the trend of the past would remain in the future. The increased herd size was incorporated in the economic module by including a dynamic herd size on yearly level. With this parameter, it was possible to correct for the fact that losses associated with BVDV infection, costs for BVDV vaccination, and costs for BVDV control on herd level are influenced by an increase in herd size. The decreasing number of herds was incorporated by including this decrease when combining all costs and losses of BVDV infections on national level.

To enable the comparison between the current situation and the scenarios in which voluntary or mandatory BVDV control programs are executed, an annual discount rate $(r)$ of $2 \%$ was included for the study period (2015-2025). In this way, some allowance was introduced for differential timing of costs and benefits. For both the current situation and the control scenarios included in the model, the total net costs (TNC) were calculated by summing all discounted annual costs (equation 8):

$$
\mathrm{TNC}=\sum_{t=1}^{10} \frac{\left(\mathrm{PL}+\mathrm{CC}_{\mathrm{vol} \_ \text {testcul }}+\mathrm{CC}_{\mathrm{vacc}}\right)_{t}}{(1+r)^{t}} .
$$

In the results, the average annual net costs $(\mathbf{m N C})$ are provided, which is the TNC divided by the total number of years that were evaluated $(10 \mathrm{yr})$. In the default model, a $2 \%$ discount rate was included to account for indexation. In a sensitivity analysis, this rate was increased to also account for opportunity costs.

A cost-benefit analysis was conducted to evaluate the profitability of the different control scenarios compared with the current situation. For each of the control strategies, the costs included the expenses for the additional measures that were implemented. The benefits included reduced production losses and reduced expenditures, for example, when vaccination was ceased. The cost and benefits depended on the actions that were taken and varied between the different control scenarios. For each of the scenarios, a $\mathrm{B} / \mathrm{C}$ ratio was calculated by dividing the total present value of the benefits by the total present value of the costs, to represent the relative size of the costs and benefits. 


\section{Validation of the Model and Sensitivity Analyses}

The model was validated using prevalence data from 2008 and 2009 as input for the model and by comparing the model output for the prevalence in 2010, 2012 , and 2014 with real outcomes of surveys in the Netherlands in those years (Brouwer-Middelesch et al., 2010, 2012; Veldhuis et al., 2014). When comparing the model outcomes with the results of the surveys, it was taken into account that the prevalence simulated by the model should be slightly higher than the result of the prevalence studies. In the prevalence studies, only the percentage of herds with an indication of virus circulation among young stock (between 8 and 12 mo of age) was evaluated. Therefore, herds with BVDV circulation among the adult cattle but without circulation of the virus among the calves were not (yet) detected.

Sensitivity analyses in @Risk were used to evaluate for which parameters the model was most sensitive by determining which of the input parameters had the strongest effect on the prevalence. These parameters were ranked by effect on the prevalence using the Spearman rank order correlation (r; Vose, 2008).

In the basic model we chose to include a $2 \%$ discount rate to translate future costs into present values. In this discount rate, no opportunity costs (the cost of an alternative that must be forgone to pursue BVDV control) were included. The exact height of the total discount rate including opportunity costs were unknown. In sensitivity analyses, the discount rate was varied to $5 \%$ and $7 \%$.

\section{BVDV Control Scenarios Added to the Model}

After validation of the model, 4 different BVDV control scenarios were added. Three of the control scenarios that were included were deduced from control programs that are currently in place in other European countries (scenario 1, 3, and 4). The costs and benefits of these control scenarios were evaluated for the Netherlands. A short description of each of the scenarios is presented below; the alterations that were made to the model for each of the scenarios are described in Appendix Table A2.

Scenario 1: obligatory tracing and removing PI cattle and monitoring of the subsequent status while vaccination for BVDV is allowed (sc1: obliged testingremoving). In this scenario, the herd BVDV status is evaluated by testing the bulk milk for BVDV and serology on 5 calves between 8 and 12 mo of age for the presence of BVDV antibodies. When evidence is present for BVDV circulation, PI cattle are traced by individual testing and removed from the herd. When all PI cattle are removed or when no PI are present in the first place, all newborn calves are tested for the presence of the BVDV during a period of 10 mo. Thereafter, the herd receives the certificate that classified the herd as BVDV free. This status is monitored twice a year by antibody testing for an indication of virus circulation in calves. In this scenario, vaccination for BVDV is allowed and it is assumed that one-third of all farmers did vaccinate.

Scenario 2: vaccination for BVDV is obligatory in all Dutch dairy herds (sc2: vaccination). In this scenario, all farmers are obliged to vaccinate their cattle twice a year (first time requires a primer vaccination) for BVDV. In this scenario, no distinction is made between farms with a different initial BVDV status. In this scenario it is assumed that the vaccine has an effectiveness of $99.9 \%$ and that the vaccine is sufficiently applied in $90 \%$ of the herds. No additional efforts are made to trace and remove PI cattle.

Scenario 3: obligatory tracing and removing of PI animals and monitoring of the subsequent status based on ear-notch sampling of newborn calves. After $3 \mathrm{yr}$, vaccination is ceased and monitoring of the BVDV status is based on biannual serological testing of 5 calves between 8 and 12 mo of age (sc3: tracing-removing earnotch). In this scenario, first the BVDV status of dairy herds that are not participating in the voluntary BVDV control program was evaluated involving serological testing of 5 calves between 8 and 12 mo of age and testing a bulk milk sample on the presence of BVDV. If this first evaluation indicates virus circulation, the PI cattle are traced and culled by individual testing. Thereafter, the status of these herds is monitored for 3 yr based on ear-notch sampling of every newborn calf. Calves that appear PI are culled immediately. Herds in which no BVDV circulation is detected are certified BVDV free (after implementing the same measures for tracing and removing of all PI as described in sc1) and are monitored accordingly. After 3 yr, all dairy herds will be monitored based on biannual serological testing of 5 calves. At the same time, herds will stop vaccinating their cattle.

Scenario 4: determining the BVDV status followed by control measures on a voluntary basis for $3 \mathrm{yr}$. After this period, obligatory tracing and removing of PI animals and monitoring of the subsequent BVDV-free status in which vaccination is allowed (sc4: voluntary-obligatory eradication). Similar to the third scenario, in the fourth scenario dairy herds that are already participating in the voluntary BVDV control program and are certified BVDV free do not have to take any additional actions besides continuing to monitor their status. Herds with an unknown BVDV status are obliged to participate with an evaluation of their BVDV status. The result of this evaluation is reported to the farmer. The farm- 
ers can then choose for 1 out of 3 subsequent options: (1) the farmer is going to trace and cull PI cattle and monitor the subsequent free status, (2) the farmer is going to monitor the situation on his farm by means of serological testing of young stock or bulk milk testing on a routine basis, or (3) no further actions are taken. After 3 yr, all dairy farms that are not officially certified BVDV free are obliged to evaluate the BVDV status of their herd again and are obliged to trace and cull the PI cattle and to subsequently test all newborn calves during a 10-mo period. Then, the BVDV status of all herds is monitored through biannual serological testing of 5 calves between 8 and 12 mo of age. Vaccination is allowed and it is assumed that the proportion of vaccinating herds stays stable during the 10-yr simulation period and remains equal to the period before implementation of the scenario.

\section{RESULTS}

\section{Validity of the Model}

The model estimated a mean BVDV prevalence of $21.0 \%$ in 2010 (5\% percentile, $18.1 \% ; 95 \%$ percentile, $24.0 \%$ ), $19.5 \%$ in 2012 (5\% percentile, $15.0 \%$; $95 \%$ percentile, $24.4 \%$ ), and $18.0 \%$ in 2014 (5\% percentile, $12.9 \%$; $95 \%$ percentile, $23.4 \%$ ). Based on the results of the surveys in which an estimate of BVDV circulation in young stock was obtained in the years 2010, 2012, and 2014, the model prevalence was slightly higher (Figure 1). This was as expected because the field studies aimed at determining virus circulation in young stock only. Both in the survey results and in the model output, a slight decrease in BVDV prevalence over time was observed in the study period (Figure 1). Based on this information, the model was assumed to give fairly realistic estimates for the actual situation in the Netherlands.

\section{Current Situation}

Based on the inputs and assumptions that were included in the model, the current situation resulted in a slight decrease in BVDV prevalence in the study period because of the voluntary control efforts that are in place. This decrease was mainly attributable to the increasing proportion of dairy farmers that either participate in the voluntary BVDV control program or that vaccinated their cattle for BVD. The model estimated that in $18 \%$ of the dairy herds a PI animal was present in 2014 and that this decreased to $13.9 \%$ in 2025 (5\% percentile: $8.9 \%$; $95 \%$ percentile: $19.3 \%$; Figure 2a).
Based on the model inputs and assumptions, NC attributable to BVD were estimated at $€ 30.8$ million in 2014 (5\% percentile: €17.2 million; $95 \%$ percentile: $€ 51.8$ million; Figure 2b). During the study period between 2015 and 2025 the $\mathrm{mNC}$ associated with BVD was $€ 27.6$ million per year ( $5 \%$ percentile: €16.4 million; $95 \%$ percentile: $€ 44.6$ million). Although both the prevalence and the total number of dairy herds were slightly decreasing, the costs remained stable up to 2018 due to a slight increase in herd size (and thus slightly higher losses per herd in case of a BVDV outbreak), an increased participation in the voluntary BVDV control program and an increase in the proportion of herds that vaccinate their cattle over time (Figure 2). After 2018, the annual net costs decreased.

From the NC associated with BVD, $61 \%$ could be attributed to production losses that occurred as a result of a BVDV outbreak, $30 \%$ was attributed to costs of vaccination and $9 \%$ was attributed to participation in voluntary BVDV control programs for individual herds in 2014. In time, the production losses are slightly decreasing because of the decreasing BVDV prevalence and incidence and the costs for vaccination and participation in the voluntary eradication program slightly increase until the moment they are assumed to remain stable when $25 \%$ of all dairy herds vaccinate and $35 \%$ of the herds participate in the voluntary control program (after 2018).

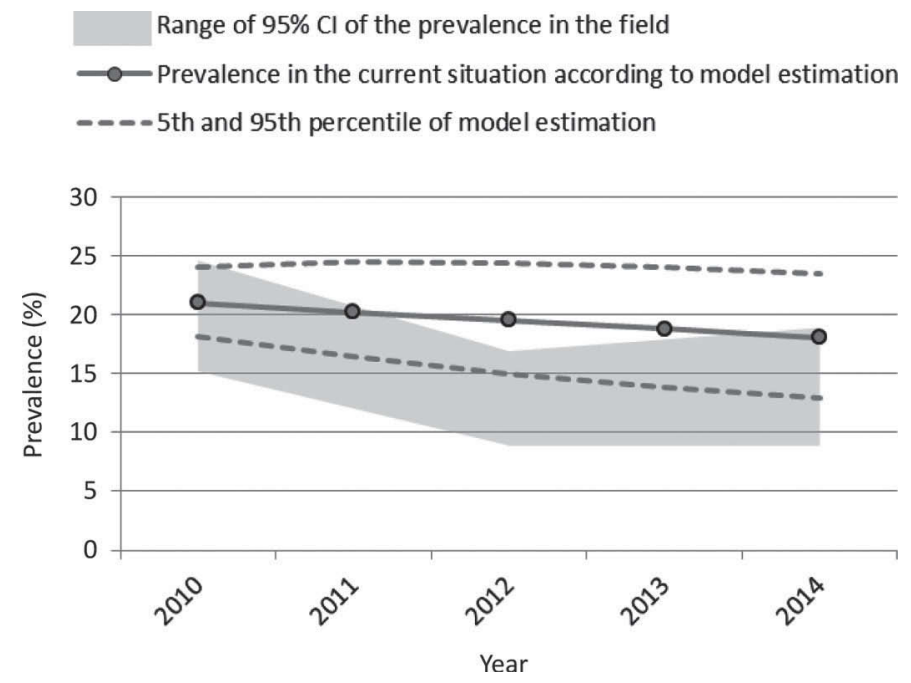

Figure 1. Mean and 5th and 95th percentile of the model output for the bovine viral diarrhea virus (BVDV) prevalence (\% herds with an indication that a PI is present) with the $95 \%$ confidence interval of the estimate of the percentage dairy herds with an indication of BVDV circulation among young stock in the Netherlands. The estimates for the years 2011 and 2013 were extrapolated based on the results that were known from 2010, 2012, and 2014. 

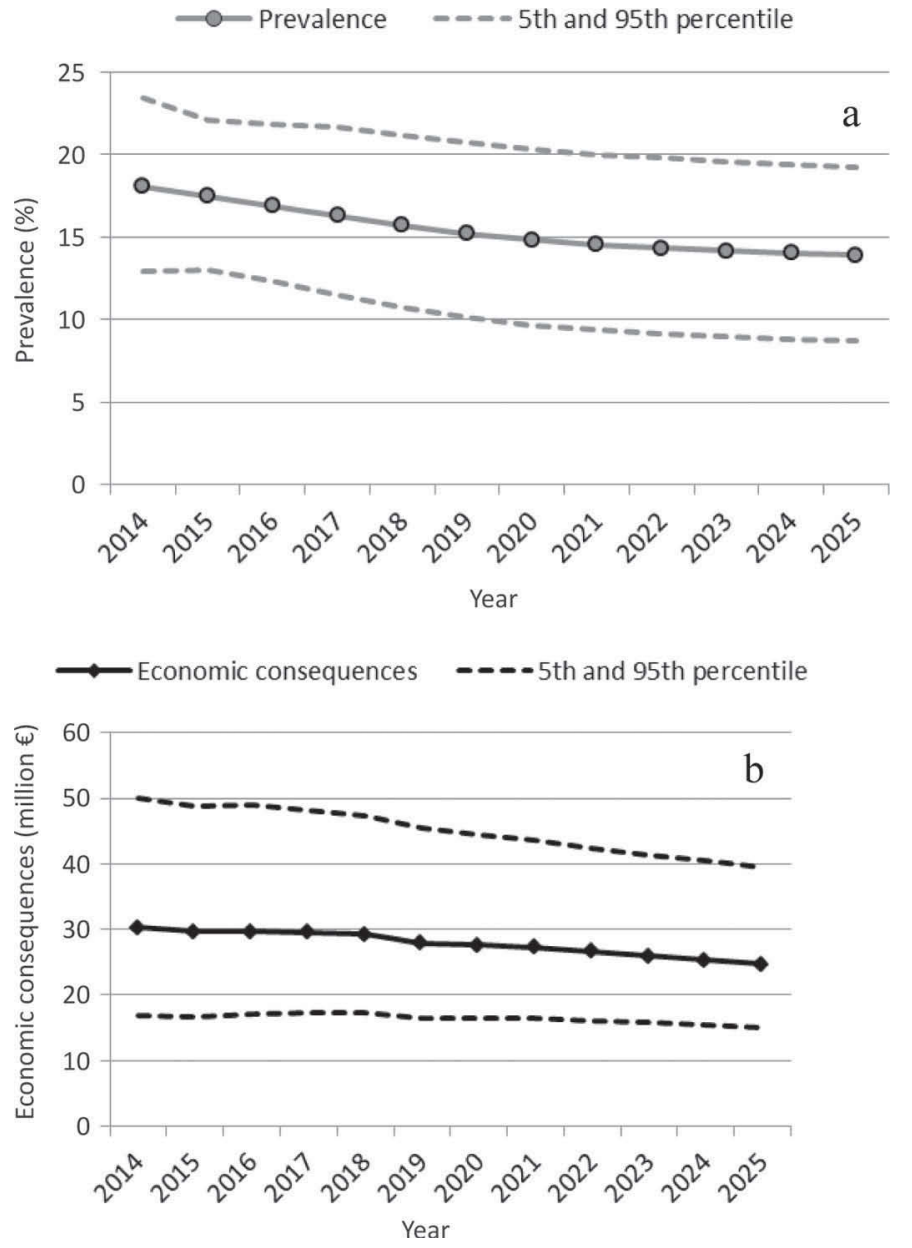

Figure 2. Mean herd bovine viral diarrhea virus (BVDV) prevalence (a) and subsequent costs in million euros $(€ ; \mathrm{b})$ with 5 th and 95th percentile in a situation with current voluntary BVDV control measures in Dutch dairy herds between 2014 and 2025.

\section{Control Scenarios}

Assuming that a risk from the nondairy herds remains (that do not actively control BVDV), it is not possible to completely eradicate BVDV in the dairy herds. The highest reduction in BVDV prevalence in the dairy herds can be obtained with the control scenario in which all dairy farms are implementing vaccination (Figure 3). With this scenario the prevalence could be reduced to $0.6 \%$ at the end of the simulated period (Table 3). However, this control scenario is the most expensive to implement ( $\mathrm{mNC} € 49.1$ million/yr) and is more costly than the current situation $(\mathrm{mNC}$ $€ 27.6$ million/yr; Table 3).

The other 3 control scenarios reduced the BVDV prevalence below $5 \%$ (Figure 3). The costs increased in the first years after implementing the control measures because of the actions that were taken to reduce the
BVDV prevalence. After these first years, for 3 control scenarios, the costs attributable to BVD reduced below those of the current situation (Figure 4)

In sc1, sc2, and sc3 an immediate reduction in BVDV prevalence is observed after implementation of the control measures (Figure 3). In sc4, which had a period of voluntary BVDV control before obligatory actions had to be taken, only a slight decrease in prevalence was observed during the voluntary period. Taking obligatory actions was more effective in reducing the prevalence (Figure 3 ). In 3 out of 4 of the control scenarios, the highest costs occurred in the first year after implementation. In the scenario in which obligatory regulation is preceded by a voluntary period ( $\mathrm{sc} 4$ ), additional control costs were observed in the year of implementation of the voluntary scenario, but the highest additional costs were observed in the year in which the control measures became obligatory (2018; Figure 4).

With sc3 (tracing and removing ear-notch) and sc4 (voluntary-obligatory eradication), the additional costs of conducting the scenario were lower compared with the monetary benefits. With sc3, the $\mathrm{B} / \mathrm{C}$ ratio was highest. Besides a reduction in prevalence, the $\mathrm{B} / \mathrm{C}$ ratio of this scenario was 1.5 , meaning that investing $€ 1$ resulted in a benefit of $€ 1.5$. With the scenario in which voluntary control was followed by obliged eradication $(\mathrm{sc} 4)$, the $\mathrm{B} / \mathrm{C}$ ratio was calculated at 1.1 (Table 3 ). One of the assumptions of scenario sc4 was that after implementation, the proportion of vaccinating herds for BVDV would remain stable. If instead the proportion of vaccinating herds would decrease, the net costs of this control scenario would decrease as well and the scenario would become more beneficial (Figure 4). Nevertheless, this would result in a slight increase in BVDV prevalence. The same was true for sc1, in which $33 \%$ of all dairy herds were assumed to vaccinate for BVDV.

From 2014 to 2025, the economic benefit of implementing sc4 was small compared with the current situation. However, at the end of the study period, the net costs attributed to BVD will always remain lower with sc4 (Figure 4). In the last year that is simulated in the model (2025), the NC associated with BVD for the current situation was estimated at $€ 24.7$ (5th and 95th percentile: €15.0-€39.4) million. With sc4, $N C$ was estimated at €21.1 (5th and 95th percentile: €13.8-€32.6) in 2025 .

\section{Sensitivity Analyses}

The sensitivity analyses showed that the model was most sensitive to alterations in the parameters that were directly associated with the BVDV incidence. The parameter that had the highest correlation with the 


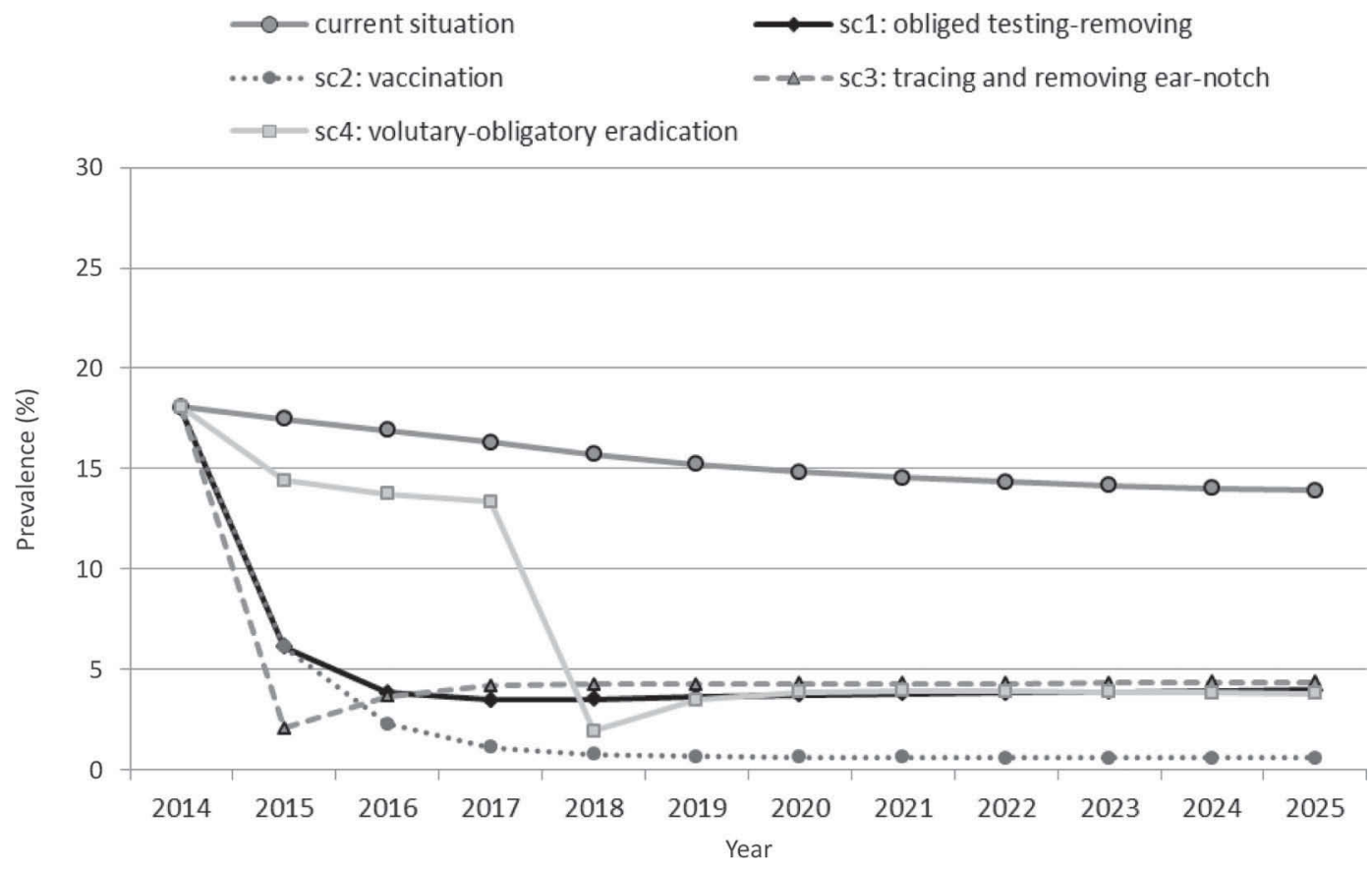

Figure 3. The mean herd prevalence of bovine viral diarrhea virus (BVDV) in Dutch dairy herds between 2014 and 2025 for the current situation and when BVDV control scenarios (sc) are implemented from 2015 on.

prevalence was the rate at which new BVDV infections occurred. The value of this parameter was based on the incidence of new infections in herds that participated in the voluntary BVDV control program and was used as the minimum incidence risk. For the most likely and maximum value, this percentage was multiplied by 1.5 and 3 , respectively. Because the maximum value was uncertain, this was varied. When the maximum value was changed to 2 times the minimum (15.6\% instead of
$23 \%$ ), the prevalence in 2014 was estimated at $17.3 \%$ (5\% percentile: $12.8 ; 95 \%$ percentile: $22.0 \%$ ) instead of $18.0 \%$. In addition, when the maximum was changed to 4 times the minimum (into $31.3 \%$ ), the prevalence in 2014 was estimated at $19.7 \%$ (5\% percentile: 13.6 ; $95 \%$ percentile: $26.5 \%$ ). The model was sensitive to the amount of risk that was assigned to nondairy herds. In the basic model, which simulated the current control efforts as well as in the control scenarios, it was assumed

Table 3. Output for the current situation and added control scenarios (CS) for bovine viral diarrhea virus (BVDV) in Dutch dairy herds between 2015 and 2025, including the BVDV prevalence at the end of the period in 2025, the annual net costs attributable to BVDV assuming an annual discount rate of $2 \%$, the results of the benefit to cost ratio (B/C ratio) for each of the control scenarios, and their subsequent economic ranking ( 1 is ranked as best)

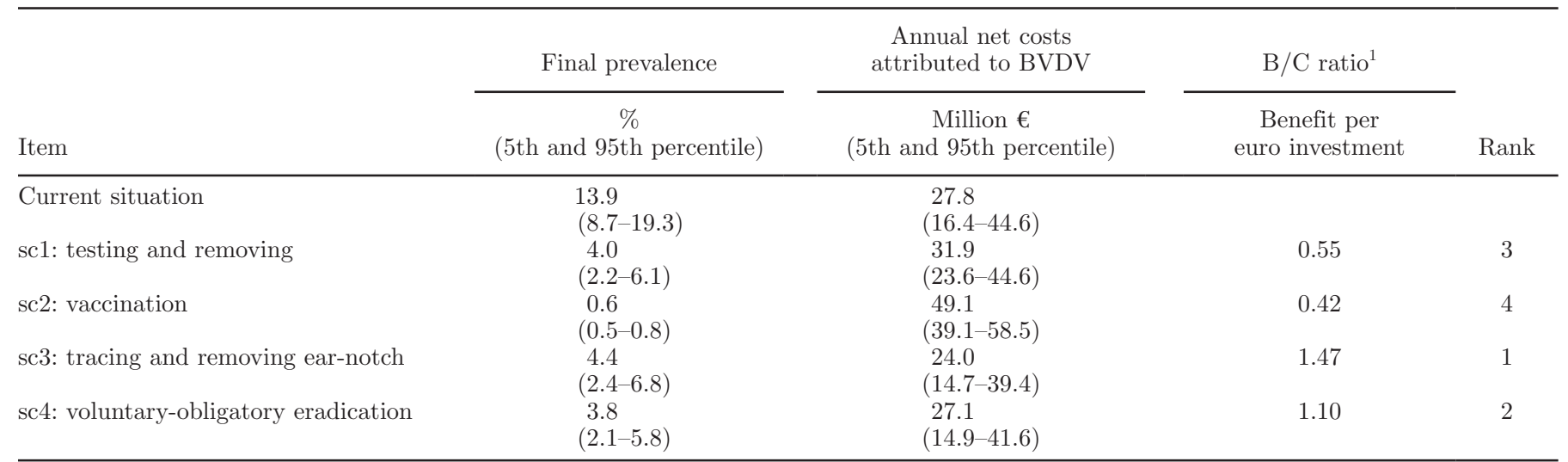

${ }^{1} \mathrm{~A} \mathrm{~B} / \mathrm{C}$ ratio $>1$ means that the benefit is higher than the cost; a $\mathrm{B} / \mathrm{C}$ ratio $<1$ means that the benefits are lower than the costs that are made for implementation of the scenario. 
that $10 \%$ of all new infections were caused by nondairy herds. However, when nondairy farmers would also decide to implement control measures, the risk of new BVDV infections that could be assigned to nondairy herds would decrease. When the risk from nondairy herds decreased by $50 \%$, the model estimated prevalences below $2.6 \%$ in 2025 for all 4 control scenarios. When there would be no risk of other nondairy herds at all, it would be possible to eradicate BVDV completely. In addition, in all but the vaccination scenario, the $\mathrm{mNC}$ attributed to BVD for dairy herds would decrease accordingly. For the vaccination scenario, $\mathrm{mNC}$ remained high in all circumstances because of the high cost of vaccinating all dairy cattle. Nevertheless, changing the amount of risk from nondairy herds did not have any effect on the ranking of the $\mathrm{B} / \mathrm{C}$ ratios between the scenarios.

An additional sensitivity analysis was conducted to gain more insight into the effects of including opportunity costs in the discount rates that were included in the economic module of the model. The results showed that, although $\mathrm{mNC}$ changed at higher discount rates, the ranking between the scenarios from cheapest to most expensive remained the same (Table 4). Including a discount rate had a minor influence on the $\mathrm{B} / \mathrm{C}$ ratio of the scenarios in which the costs made for BVDV control were more equally distributed over the simulated years. This was the case in sc1 in which, besides costs of monitoring the BVDV-free status, additional annual costs were incurred for vaccinating $33 \%$ of the cattle and in sc2 in which high annual costs were incurred for vaccinating all cattle throughout the study period. By including higher discount rates, the $\mathrm{B} / \mathrm{C}$ ratios of sc3 and sc4 became less beneficial (Table 4). In both scenarios, the majority of the costs were made in the first years after implementation.

\section{DISCUSSION}

This paper presents a model that simulates the effect of control scenarios on the prevalence and net costs associated with BVD for the Dutch dairy industry.

The results of the scenarios showed that it is possible to implement BVDV control scenarios that are beneficial. In 2 out of the 4 scenarios presented in this paper, the benefits of reducing BVD attributable losses were higher than the additional costs for conducting the control scenario (Table 3). Nevertheless, the confidence intervals of both scenarios that were cost-effective show an overlap with the net costs of the current situation over the whole study period. However, after the 10-yr period that is included in the model (after 2025), the net costs of the control scenarios will always remain lower compared with the present situation in which no additional control measures are taken. In addition, in both sc1 and sc4, some of the farmers still continue

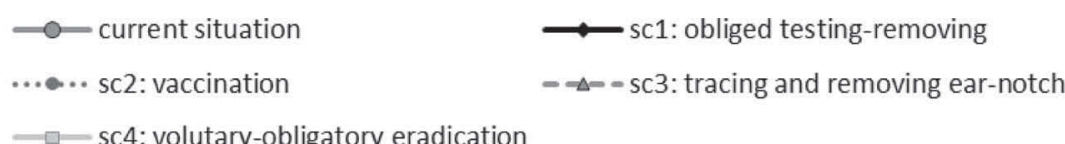

$\square-$ sc4: volutary-obligatory eradication

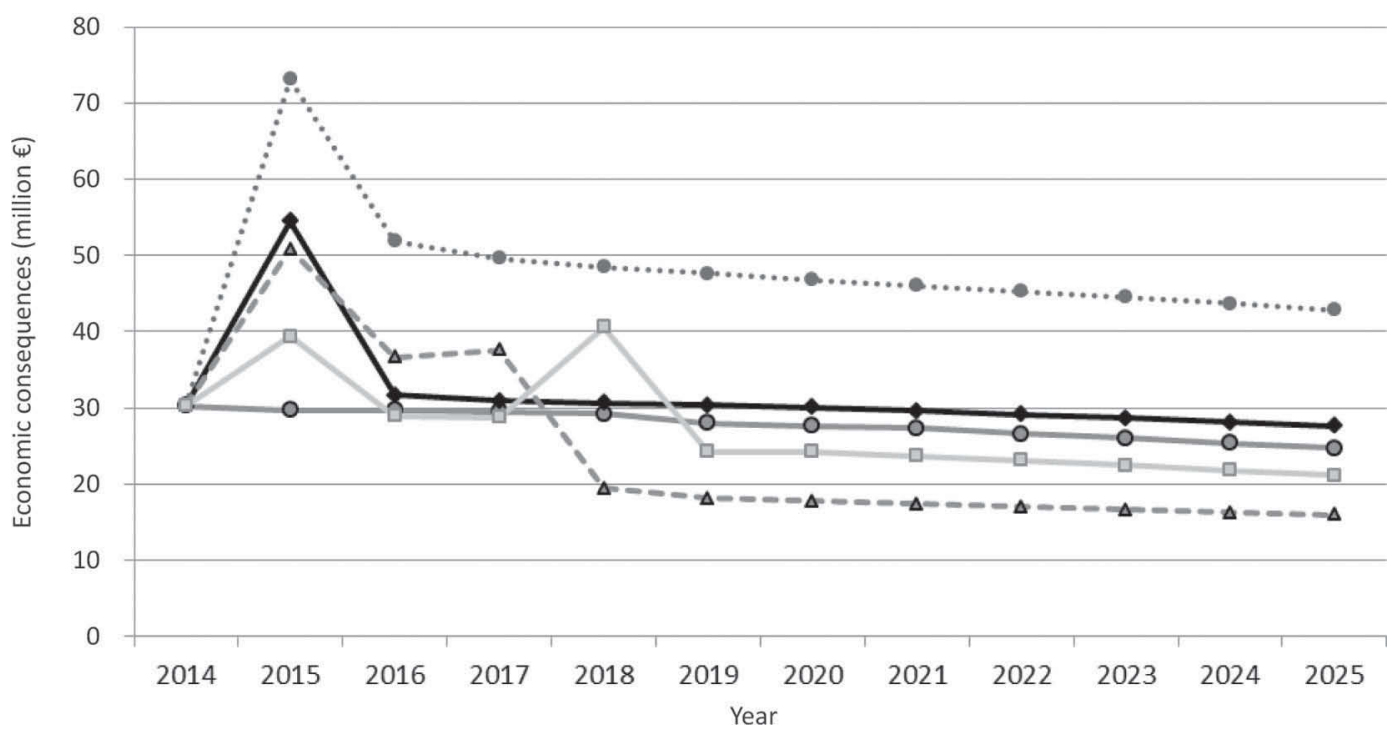

Figure 4. The costs that can be attributed to bovine viral diarrhea virus (BVDV) in Dutch dairy herds between 2014 and 2025 for the current situation and when BVDV control scenarios (sc) are implemented from 2015 on. 
vaccinating their cows for BVDV during the study period. This is a substantial part of the net costs in these control scenarios. When, in the control scenarios, the BVDV incidence risk is (very) low, it is possible that farmers stop vaccinating their cattle. In this case, the costs of the scenarios will also decrease greatly with only a small decrease in benefits (results not presented) and sc1 will become more beneficial than the current situation as well.

The model output showed that BVDV can only be eradicated with these control scenarios when the risk of spread of BVDV from nondairy herds is eliminated as well. To achieve this, it is important that nondairy herds also implement control scenarios. Stott et al. (2012) estimated that it was beneficial to attempt to eradicate BVDV from beef suckler herds in Ireland. However, in the Netherlands the beef suckler industry is small and is not comparable with that of Ireland. From a model that evaluated the costs and benefits of control scenarios in the beef suckler industry in the Netherlands, it was concluded that the benefits of BVDV control were slightly smaller than the net costs (results not presented). Nevertheless, the additional benefits of BVDV control in beef suckler herds for the cattle industry as a whole are high and beneficial.

Our findings were in accordance with many other studies that evaluated BVDV control. Løken and Nyberg (2013) evaluated the BVDV eradication project in Norwegian cattle. Using a test, trace, and cull program (comparable to sc1 without additional vaccination), it was possible to reduce the BVDV prevalence to $0.01 \%$ after $10 \mathrm{yr}$. With this program, the annual losses that were saved were estimated between €5.9 to €23.7 mil- lion against additional program costs of $€ 0.6$ million/yr. In Norway, eradication was estimated to have a higher cost-benefit ratio than was estimated from the control scenarios included in our study. These differences can be explained by the differences in the initial situation before starting the control program and the role of vaccination. In Norway, vaccination is prohibited, whereas in our study, in all scenarios the costs and benefits of vaccination were included. The program that was used to control BVDV in Switzerland, which was comparable with sc3 in our study, showed that the prevalence of BVDV can be reduced very quickly when combining a whole herd screening with ear-notch sampling of newborn calves (Presi et al., 2011). Their program started in 2008, and the break-even point where the investments for eradication were equal to the losses when no additional actions were taken was estimated to be reached in 2012 (Häsler et al., 2012). Stott et al. (2012) presented results of bio-economic models in which the costs and benefits of a 6-yr eradication program of BVDV in Ireland were evaluated using 5 interrelated virological and serological testing programs. Again it was found that it was highly economically beneficial to implement a BVDV eradication program because the model estimated that the annual benefits exceeded the costs by a factor of 5 in the beef suckler sector and a factor of 14 in the dairy sector. Based on these findings, several countries in north-west Europe are implementing BVDV control programs (Presi and Heim, 2010; Tavella et al., 2012; BVD Policy Team Scotland, 2014).

The model simulated transmission between herds, where herds could have 1 out of 4 BVDV statuses. In the model it was assumed that only herds with sta-

Table 4. Output of the sensitivity analyses on varying the discount percentage that is included in the economic module of the SIRV (susceptibleinfectious-recovered-vaccinated) model $^{1}$

\begin{tabular}{|c|c|c|c|c|c|c|}
\hline \multirow[b]{2}{*}{ Item } & \multicolumn{3}{|c|}{$\begin{array}{c}\mathrm{mNC} \\
\text { (5th and 95th percentile) }\end{array}$} & \multicolumn{3}{|c|}{$\mathrm{B} / \mathrm{C}$ ratio $^{2}$} \\
\hline & $\begin{array}{c}2 \% \\
\text { Discount } \\
\text { rate (default) }\end{array}$ & $\begin{array}{l}5 \% \\
\text { Discount } \\
\text { rate }\end{array}$ & $\begin{array}{l}7 \% \\
\text { Discount } \\
\text { rate }\end{array}$ & $\begin{array}{c}2 \% \\
\text { Discount } \\
\text { rate (default) }\end{array}$ & $\begin{array}{c}5 \% \\
\text { Discount } \\
\text { rate }\end{array}$ & $\begin{array}{c}7 \% \\
\text { Discount } \\
\text { rate }\end{array}$ \\
\hline Current situation & $\begin{array}{l}27.8 \\
(16.4-44.6)\end{array}$ & $\begin{array}{l}23.1 \\
(13.8-37.5)\end{array}$ & $\begin{array}{l}20.7 \\
(12.2-33.5)\end{array}$ & & & \\
\hline $\mathrm{sc} 2$ : vaccination & $\begin{array}{l}49.1 \\
(39.1-58.5)\end{array}$ & $\begin{array}{l}41.4 \\
(33.0-49.3)\end{array}$ & $\begin{array}{l}37.1 \\
(29.5-44.2)\end{array}$ & 0.42 & 0.41 & 0.41 \\
\hline sc3: tracing and removing ear-notch & $\begin{array}{l}24.0 \\
(14.7-39.4)\end{array}$ & $\begin{array}{l}20.7 \\
(13.1-33.0)\end{array}$ & $\begin{array}{l}19.8 \\
(12.4-31.7)\end{array}$ & 1.47 & 1.35 & 1.28 \\
\hline sc4: voluntary-obligatory eradication & $\begin{array}{l}27.1 \\
(14.9-41.6)\end{array}$ & $\begin{array}{l}23.0 \\
(15.3-35.4)\end{array}$ & $\begin{array}{l}20.7 \\
(13.7-30.7)\end{array}$ & 1.10 & 1.02 & 1.00 \\
\hline
\end{tabular}

${ }^{1}$ The results are presented by the average annual net costs $(\mathrm{mNC})$ and the benefit to cost ratio (B/C ratio) of bovine viral diarrhea virus in Dutch dairy herds for each scenario (sc) between 2015 and 2025.

${ }^{2} \mathrm{~A}$ B/C ratio $>1$ means that the benefit is higher than the cost; a $\mathrm{B} / \mathrm{C}$ ratio $<1$ means that the benefits are lower than the costs that are made for implementation of the scenario. 
tus I could infect other herds and that a S herd could only evolve to status I after introduction of PI cattle either by purchase or birth. This meant that herds in which a pregnant cow was purchased carrying a PI fetus remained susceptible until the PI was born. These herds, which were classified as S, could in theory infect other herds when selling the pregnant cow carrying the PI, while we assumed that purchasing cattle from $\mathrm{S}$ herds holds no risk. Although we probably slightly underestimated the risk of introduction with the definitions of the various states that we used, in practice it is very unlikely that a herd that bought a pregnant cow carrying a PI would sell this cow before calving and subsequently infect another herd. Furthermore, it is likely that transmission of BVDV will not occur until the PI is born and thus contacts with this herd before the birth of the PI will not lead to spread of the virus between herds. In addition, in the model it was assumed that herds with status $\mathrm{R}$ were protected against new BVDV infections and subsequent losses and that herds with status $\mathrm{S}$ were completely susceptible for a new BVDV infection with subsequent losses. This was a simplification of reality because herds with 50 to $100 \%$ ( $\mathrm{R}$ herds) seropositive cattle still may have susceptible cows present and can get infected and suffer from subsequent losses. On the other hand, in susceptible herds, seropositive cattle might be present, which will reduce the losses when a new BVD outbreak occurs. These assumptions might lead to an overestimate of the net costs of BVD outbreaks in S herds and underestimation of the net costs in R herds. Altogether, it is assumed that this simplification has little effect on the estimated net costs of BVDV for the complete dairy industry. Further, the main aim of this study was to compare different control and eradication scenarios, and if a slight under- or overestimation in losses due to a BVDV outbreak would remain, this would be the case in all scenarios and would therefore have no effect on the subsequent economic ranking.

In the model, the duration of an average dairy herd in the $\mathrm{R}$ status was 22 to $30 \mathrm{mo}$ (most likely $26 \mathrm{mo}$ ). Given the actual replacement percentages (25 to 30\%) in the Netherlands, it was assumed that, after this period, more than $50 \%$ of the cattle (including adult cows, young stock, and calves) in the herd would be seronegative again. Although, after thorough consultation with the experts, the 26-mo period seemed valid for the Dutch situation (given the housing systems applied), it might be that the distribution of the seronegative cattle is not always equally divided across the different age categories of cattle present depending on the housing system (i.e., higher in calves and young stock if they had been in contact with the PI, versus lower in adult cows). In the case that the whole herd seroconverts, the seroprevalence in adult cattle might still be higher than $50 \%$ after 26 mo. In these herds, the losses due to BVDV infection will be overestimated if a new infection occurs shortly after this 26-mo period. Nevertheless, given the BVDV incidence in the Netherlands, the probability to be infected shortly after entering the $\mathrm{S}$ status is fairly low. The effect of increasing the duration in the $\mathrm{R}$ status was evaluated in a sensitivity analysis (results not shown). The model outputs only differed slightly and the conclusions were not affected by the change of this parameter. When the most likely duration of 26 mo in the $\mathrm{R}$ status was increased to $36 \mathrm{mo}$ ( $75 \%$ of the cattle population that was present during the BVDV infection would be replaced after that period), both the prevalence and economic consequences showed a slight decrease in all scenarios. The ranking of the different scenarios was not changed.

Although from the literature, it is known that birth of PI calves is not completely prevented after vaccination with inactivated vaccines (Rodning et al., 2010), in the model, it was assumed that vaccinated herds did not spread BVDV. In consultation with our experts, we assumed that no PI cattle were left in herds that already vaccinated for multiple years. Furthermore, when the reason to start vaccinating for BVDV was an indication of presence of the virus, in general, Dutch veterinarians advised to trace and cull the PI cattle first. Nevertheless, this assumption might have slightly underestimated the risk of vaccinated herds for both the current situation and all simulated scenarios.

It was assumed that the probability of starting to vaccinate in S, I, and $\mathrm{R}$ herds was identical. In reality, infected (I) herds might have a higher probability to begin vaccinating. This could not be supported by actual data and therefore it was decided to assume equality. Including a higher probability of vaccination in infected herds could potentially result in a higher benefit of vaccination but would not have changed the economic ranking of the scenarios. On the other hand, in the model the efficacy of vaccination was assumed to be close to $100 \%$ if the farmer carefully followed the manufacturers' instructions (assumed to be $90 \%$ of the farmers). If the efficacy would be lower, this would result in a higher proportion of recurring BVDV infections despite vaccination and would result in higher economic costs in both the current situation and also in sc1 and sc2 where vaccination is part of the control program.

The state-transition model that was used for this study usually assumes homogeneous mixing, which may not be valid at herd level. Therefore, in our model, a generic modification based on actual field data was included to roughly account for the heterogeneity of contacts between dairy herds. In this modification, 
the probability to evolve from state $\mathrm{S}$ to state I was depending on a basic risk component and 3 known risk factors (i.e., purchase of cattle, over-the-fence contacts between cattle, and raising young stock at other farms). The same modification was applied to the probability to evolve from state I to state R, which assumed different infectious periods depending on participation in a BVDV control program. This was a simplification of reality and was chosen instead of including different compartments for herds with a higher influx (i.e., for herds that frequently purchased cattle) or outflux (i.e., for herds that participated in the BVDV control program) of BVDV infections. This method would have been more appropriate to estimate the risk-based effects of BVDV control but we aimed at estimating the effect of BVDV control in time for the average Dutch dairy herd. We adapted the method from the study of Bergevoet et al. (2009) on control programs for Salmonella. Using this method enabled us to implement time-dependent variation such as increasing herd sizes, increase in participation in the voluntary BVDV control program, and increasing percentages of herds vaccinating their cattle that we observed in the field, in our model. Further, with this method it was possible to simulate scenarios in which we changed the control measures after the first years of implementation $(\mathrm{sc} 3$ and $\mathrm{sc} 4$ ).

In the model, the risk of introduction of BVDV depends on 3 known risk factors and an unknown basic component covering BVDV infections that could not be traced back to one of the known risk factors. From the literature, it is known that direct contact between animals is the most effective way for BVDV to spread and that spread through indirect contacts is less common due to the fact that BVDV does not survive well in the environment (Tremblay, 1996; Lindberg and Alenius, 1999). With these 3 risk factors and the inclusion of a basic risk accounting for the unknown risk factors that could not be quantified, we think that the model represents a fairly complete indication of the risk for introduction of the virus. It was assumed that $10 \%$ of the new BVDV infections were caused by nondairy herds that are not implementing any control measures. Because the prevalence of BVDV in nondairy herds is similar to the BVDV prevalence in dairy herds, the amount of contacts between dairy and nondairy herds is limited and the fact that given BVDV control in the dairy industry the prevalence of BVDV is likely to reduce in nondairy herds as well, the $10 \%$ of the total introduction risk that is accounted for by contacts with nondairy herds might be an overestimation. Reducing this risk in sensitivity analyses, resulted in higher B/C ratio for all scenarios included but did not change the ranking. Other influential input parameters were the time until recovery and the time from recovery until becoming susceptible, which were based on census data (replacement rates), data from the voluntary BVDV eradication program, and information from the publication of Viet et al. (2004). These input parameters were deemed valid and were not varied in the sensitivity analyses.

For the calculation of the losses due to a BVDV infection, estimates of a study conducted by Hogeveen et al. (2003) were used. In this study, the losses of BVDV infections in milking cows were simulated using, among others, the results of economic studies that were conducted in Dutch dairy herds as input (Wentink and Dijkhuizen, 1990; Pasman et al., 1994). These studies all exclusively included direct losses associated with BVDV infection such as effects of BVDV infections on still births, birth of small and weak calves, decreased growth rates, decreased milk production, disease and mortality of cattle, decreased fertility, increased abortion rates, and losses associated with PI (i.e., mucosal disease). Indirect losses associated with a decreased resistance and resilience against other infections were not included. Further, the losses were all exclusively based on milking cows; losses caused by infections in calves and young stock were not included and were assumed nonexistent. Losses associated with BVDV infections may therefore be slightly underestimated. Higher losses associated with BVD will result in a higher $\mathrm{B} / \mathrm{C}$ ratio of all 4 scenarios included.

In the model, it was assumed that tracing and culling PI cattle resulted, among other things, in replacement costs of the PI that had to be culled. For the estimation of the replacement costs, actual replacement values calculated by the Livestock Economic Institute in the Netherlands were used (KWIN, 2010). It might be that the replacement value of PI cattle is lower compared with those of non-PI. Nevertheless, no information was available on the actual replacement value of PI and therefore it was decided to use actual values instead. This overestimation in replacement value might result in a slight underestimated $\mathrm{B} / \mathrm{C}$ ratio for the scenarios in which farmers are tracing and culling PI cattle (sc1, 3 , and 4). In the cost-benefit analysis, a reduction in losses due to BVDV infections and reduced expenditures due to a decreasing need for vaccination in sc3 and sc4, or a decreasing need for a voluntary BVDV control program in sc2, were included as benefits. Besides these benefits, several benefits were found that could not be monetized such as increased welfare, a more positive public opinion of the dairy industry as a whole, and an increased value of BVDV-free export cattle.

In the default model, a low discount rate of $2 \%$ per year was included to make future costs and benefits comparable to present values. This discount rate of $2 \%$ 
differed from the $2.5 \%$ rate that was used to translate the losses associated with BVD in 2003 (Hogeveen et al., 2003) to current values. This lower discount rate for future compared with past costs and benefits was chosen because of the differences between the historic economic environment and the current and predicted economic environment. In a sensitivity analysis, the discount rate was increased to represent not only an indexing parameter, but also the combination of indexing and opportunity costs. The results showed that the ranking of the scenarios from most to least beneficial remained the same. Increasing the discount rates decreased the economic value of production losses associated with BVD in later years in the current situation. This resulted in reduced economic benefits in sc3 and sc4 compared with the current situation. In these scenarios, the majority of the control costs were made directly after implementing the national control scenarios. A 7\% discount rate that includes high opportunity costs might not be very realistic, given the need to control BVDV in the Netherlands to reach a comparable health status with other (neighboring) EU countries (e.g., Germany and Belgium) for trading purposes. Nevertheless, even if an annual discount rate of $7 \%$ was applied, both scenarios remained economically beneficial.

Even though the simulation model is a simplification of reality, we were able to include many input parameters that were based on census data or BVDV field data. In addition, the outputs of the model showed that the trend in prevalence roughly approximated the trend that was visible in the field. This indicated that the model could be used to simulate the relative effects of different BVDV control scenarios.

The results of this model might also be valid for other countries with comparable herd sizes (approximately 90 cows $>2$ yr old) that have a comparable housing (mostly free stall barns), grazing system (summer grazing on approximately $2 / 3$ of all dairy herds), and management system. The level of the BVDV prevalence and incidence will differ between countries, which will result in different economic losses associated with BVD in an endemic situation. In the Netherlands, the BVDV prevalence was already fairly low as a result of all the voluntary efforts of dairy farmers. Therefore, the economic gain of implementing collective control programs in the Netherlands will probably be lower compared with countries, with a comparable dairy industry, in which the prevalence is higher and less voluntary control efforts are taken. Nevertheless, the ranking between the scenarios is robust and not sensitive to the prevalence level at the start of the program and will probably be comparable between different countries in which the dairy industry is comparable. Therefore the ranking of the BVDV control scenarios in this study may also be valid for other countries.

\section{CONCLUSIONS}

From this study, we conclude that it is beneficial to implement control scenarios for BVDV in the Dutch dairy industry with scenarios that involve testing and removing of PI cattle. When implementation of control scenarios lead to a decrease in the proportion of herds vaccinating for BVDV, the benefits might even be higher. The results showed that it is profitable to implement a national BVDV control program in the Netherlands, which supported policy makers in their decisions about BVDV control. It is recommended that BVDV control scenarios are not only implemented in the dairy but also in the beef industry to maximize the benefit of BVDV control.

\section{ACKNOWLEDGMENTS}

We thank the Dutch Commodity Board for Livestock and Meat (PVE, Zoetermeer, the Netherlands), the Dutch Commodity Board for Dairy (PZ, Zoetermeer, the Netherlands), and the Ministry of Economic Affairs (EZ, The Hague, the Netherlands) for funding the study.

\section{REFERENCES}

Barrett, D. J., S. J. More, D. A. Graham, J. O'Flaherty, M. L. Doherty, and H. M. Gunn. 2011. Considerations on BVDV eradication for the Irish livestock industry. Ir. Vet. J. 64:12.

Bartels, C. J. M., I. M. G. A. Berends, H. Brouwer-Middelesch, A. Damhuis, and G. Van Schaik. 2008. Report specific monitoring in 2007/2008 in Dutch: Eindrapportage specifieke monitoring 2007/2008. GD Deventer, the Netherlands.

Beaudeau, F., and C. Fourichon. 1998. Estimating relative risk of disease from outputs of logistic regression when the disease is not rare. Prev. Vet. Med. 36:243-256.

Bergevoet, R. H. M., G. Van Schaik, J. Veling, G. B. C. Backus, and P. Franken. 2009. Economic and epidemiological evaluation of Salmonella control in Dutch dairy herds. Prev. Vet. Med. 89:1-7.

Brouwer-Middelesch, H., M. Gonggrijp, and A. M. G. Deterink-Damhuis. 2012. Report specific monitoring in 2011/2012 in Dutch: Eindrapportage specifieke monitoring 2011/2012. GD Deventer, the Netherlands.

Brouwer-Middelesch, H., I. M. G. A. Santman-Berends, A. M. G. Deterink-Damhuis, and G. Van Schaik. 2010. Report specific monitoring in 2009/2010 in Dutch: Eindrapportage specifieke monitoring 2009/2010. GD Deventer.

BVD Policy Team Scotland. 2014. Farmers guidance BVD Eradication Scheme. Accessed Oct. 26, 2014. http://www.gov.scot/Topics/ farmingrural/Agriculture/animal-welfare/Diseases/disease/bvd/ eradication.

Courcoul, A., and P. Ezanno. 2010. Modelling the spread of Bovine Viral Diarrhoea Virus (BVDV) in a managed metapopulation of cattle herds. Vet. Microbiol. 142:119-128.

Cowley, D. J. B., T. A. Clegg, M. L. Doherty, and S. J. More. 2012. Bovine viral diarrhoea virus seroprevalence and vaccination usage in dairy and beef herds in the Republic of Ireland. Ir. Vet. J. $65: 16-24$. 
Evermann, J. F., and G. M. Barrington. 2005. Clinical Features. Pages 105-119 in Bovine Viral Diarrhoea Virus - Diagnosis, Management and Control. 1st ed. S. M. Goyal and J. F. Ridpath, ed. Blackwell Publishing, Ames, IA.

Ezanno, P., C. Fourichon, and H. Seegers. 2008. Influence of herd structure and type of virus introduction on the spread of bovine viral diarrhoea virus (BVDV) within a dairy herd. Vet. Res. 39:39.

Fourichon, C., F. Beaudeau, N. Bareille, and H. Seegers. 2005. Quantification of economic losses consecutive to infection of a dairy herd with bovine viral diarrhoea virus. Prev. Vet. Med. 72:177-181.

Häsler, B., K. S. Howe, P. Presi, and K. D. Stärk. 2012. An economic model to evaluate the mitigation programme for bovine viral diarrhoea in Switzerland. Prev. Vet. Med. 106:162-173.

Hogeveen, H., R. B. M. Huirne, and M. P. M. Meeuwissen. 2003. Verzekeren van diergezondheid in de melkveesector; een risicoanalyse. IRMA, Wageningen, the Netherlands.

Houe, H. 1995. Epidemiology of bovine virus diarrhoea virus. Vet. Clin. North Am. Food Anim. Pract. 11:521-547.

Houe, H. 1999. Epidemiological features and economical importance of bovine viral diarrhoea virus (BVDV) infections. Vet. Microbiol. 64:89-107.

Houe, H. 2003. Economic impact of BVDV infection in dairies. Biologicals 31:137-143.

Houe, H. 2005. Risk assessment. Pages 35-64 in Bovine Viral Diarrhoea Virus - Diagnosis, Management and Control. 1st ed. S. M. Goyal and J. F. Ridpath, ed. Blackwell Publishing, Ames, IA.

Houe, H., A. Lindberg, and V. Moennig. 2006. Test strategies in bovine viral diarrhoea virus control and eradication campaigns in Europe. J. Vet. Diagn. Invest. 18:427-436.

KWIN. 2010. Quantitative Information Livestock Industry 2009-2010 (in Dutch). Livestock Research Wageningen, Wageningen, the Netherlands.

Lindberg, A., and S. Alenius. 1999. Principles for eradication of bovine viral diarrhea virus (BVDV) infections in cattle populations. Vet. Microbiol. 64:197-222.

Lindberg, A., J. Brownlie, G. J. Gunn, H. Houe, V. Moennig, H. W Saatkamp, T. Sandvik, and P. S. Valle. 2006. The control of bovine viral diarrhoea virus in Europe: Today and in the future. Rev. Sci. Tech. 25:961-979.

Lindberg, A., and H. Houe. 2005. Characteristics in the epidemiology of bovine viral diarrhea virus (BVDV) of relevance to control. Prev. Vet. Med. 72:55-73.

Lindberg, A. L. 2003. Bovine viral diarrhoea virus infections and its control. A review. Vet. Q. 25:1-16.

Løken, T., and O. Nyberg. 2013. Eradication of BVDV in cattle: The Norwegian project. Vet. Rec. 172:661 http://dx.doi.org/10.1136/ vr.101525.

Mars, M., and C. Van Maanen. 2005. Diagnostic assays applied in BVDV control in the Netherlands. Prev. Vet. Med. 72:43-48.

McGowan, M. R., P. D. Kirkland, S. G. Richards, and I. R. Littlejohns. 1993. Increased reproductive losses in cattle infectious with bovine viral diarrhea virus infection around the time of insemination. Vet. Rec. 133:39-43.

Meier, N., G. Wittkowski, M. Alex, and A. Gangl. 2010. BVDV eradication will become mandatory for all German states as from 2011. In 26th World Buiatrics Congress, Santiago, Chile. Accessed Sep. 14, 2014. http://www.originalprocess.it/wbc2010/AbstractCD/ pdf/274.pdf.

Pasman, E. J., A. A. Dijkhuizen, and G. H. Wentink. 1994. A statetransition model to simulate the economics of bovine virus diarrhea control. Prev. Vet. Med. 20:269-277.

Potgieter, L. N. 1988. Immunosuppression in cattle as a result of bovine viral diarrhoea virus infection. Agric. Pract. 9:7-19.

Potgieter, L. N. 1995. Immunology of bovine viral diarrhea virus. Vet. Clin. North Am. Food Anim. Pract. 11:501-520.

Presi, P., and D. Heim. 2010. BVD eradication in Switzerland-A new approach. Vet. Microbiol. 142:137-142.

Presi, P., R. Struchen, T. Knight-Jones, S. Scholl, and D. Heim. 2011. Bovine viral diarrhoea (BVD) eradication in Switzerland-Experiences of the first two years. Prev. Vet. Med. 99:112-121.
Rodning, S. P., M. S. Marley, Y. Zhang, A. B. Eason, C. L. Nunley P. H. Walz, K. P. Riddell, P. K. Galik, B. W. Brodersen, and M. D. Givens. 2010. Comparison of three commercial vaccines for preventing persistent infection with bovine viral diarrhea virus. Theriogenology 73:1154-1163.

Rüfenacht, J., P. Schaller, L. Audige, M. Strasser, and E. Peterhans. 2000. Prevalence of cattle infected with bovine viral diarrhoea virus in Switzerland. Vet. Rec. 147:413-417.

Sarrazin, S., J. Dewulf, E. Matthijs, J. Laureyns, L. Mostin, and A. B. Caij. 2013. Virulence comparison and quantification of horizontal bovine viral diarrhoea virus transmission following experimental infection in calves. Prev. Vet. Med. 108:28-37.

Stelwagen, J., and A. A. Dijkhuizen. 1998. BVD-outbreak in a dairy farm may be costly: A case report. Tijdschr. Diergeneeskd. 123:283-286. (in Dutch).

Stott, A. W., R. W. Humphry, G. J. Gunn, I. Higgins, T. Hennessy, J. O'Flaherty, and D. A. Graham. 2012. Predicted costs and benefits of eradicating BVDV from Ireland. Ir. Vet. J. 65:12-21.

Tavella, A., P. Zambotto, E. Stifter, D. Lombardo, M. Rabini, E. Robatscher, and G. Brem. 2012. Investigation to the specificity of positive BVDV results in ear notch samples: Review on the fiveyear-old experience in the autonomous province of Bolzano (Italy). Berliner und Munchener Tierartz. Wochens. 125:326-331.

Tinsley, M., F. I. Lewis, and F. Brülisauer. 2012. Network modeling of BVD transmission. Vet. Res. 43:11. http://dx.doi. org/10.1186/1297-9716-43-11.

Tremblay, R. 1996. Transmission of bovine viral diarrhea virus. Vet. Med. 91:858-866.

Valle, P. S., S. W. Martin, R. Tremblay, and K. Bateman. 1999. Factors associated with being a bovine-virus diarrhoea (BVD) seropositive dairy herd in the Møre and Romsdal County of Norway. Prev. Vet. Med. 40:165-177.

Valle, P. S., E. Skjerve, W. Martin, R. B. Larssen, O. Osteras, and O. Nyberg. 2005. Ten years of bovine virus diarrhoea virus (BVDV) control in Norway: A cost-benefit analysis. Prev. Vet. Med. 72:189-207.

Van Oirschot, J. T. 1983. Congenital infections with nonarbo togavirusses. Vet. Microbiol. 8:321-361.

van Schaik, G., Y. H. Schukken, M. Nielen, A. A. Dijkhuizen, H. W. Barkema, and G. Benedictus. 2002. Probability of and risk factors for introduction of infectious diseases into Dutch SPF dairy farms: A cohort study. Prev. Vet. Med. 54:279-289.

Veldhuis, A., S. Kalkers, H. Brouwer, G. Van Schaik, and C. Roos, 2014. Report specific monitoring in 2013/2014 Dutch: Eindrapportage specifieke monitoring 2013/2014. Number 1026002, GD Deventer.

Viet, A. F., C. Fourichon, and H. Seegers. 2005. Assessment of strategies to control BVDV spread in a dairy herd using computer simulation. Prev. Vet. Med. 72:99-102.

Viet, A. F., C. Fourichon, H. Seegers, C. Jacob, and C. GuihenneucJouyaux. 2004. A model of the spread of the bovine viral-diarrhoea virus within a dairy herd. Prev. Vet. Med. 63:211-236.

Voas, S. 2012. Working together to eradicate BVD in Scotland. Vet. Rec. 170:278-279.

Vose, D. 2008. Risk Analysis, A Quantitative Guide, 3rd ed. John Wiley and Sons Ltd., Chichester, West Sussex, UK.

Waage, S. 2000. Influence of new infection with bovine virus diarrhoea virus on udder health in Norwegian dairy cows. Prev. Vet. Med. 43:123-135.

Wentink, G. H., and A. A. Dijkhuizen. 1990. Economic effects of infection with the Bovine Virus Diarrheau Virus (BVD virus) on fourteen dairy farms (in Dutch). Tijdschrift voor diergeneeskune 115:1031-1040.

Wilhelmsen, C. L., S. R. Bolin, J. F. Ridpath, N. F. Cheville, and J. P. Kluge. 1990. Experimental primary postnatal bovine viral diarrhoea viral infections in six-month old calves. Vet. Pathol. $27: 235-243$ 


\section{APPENDIX}

Table A1. Values and @Risk ${ }^{1}$ distributions that were used as input parameters or for validation of the model

\begin{tabular}{|c|c|c|}
\hline Description input parameter $^{2}$ & Value or distribution & Source \\
\hline Incidence risk of new BVDV infections in certified BVDV-free farms & $0.078 / \mathrm{yr}$ & $\begin{array}{l}\text { Data of the BVDV control program (GD } \\
\text { Animal Health) }\end{array}$ \\
\hline Incidence risk of BVDV in all dairy herds & @Risk Pert $(0.078 ; 0.117 ; 0.237)$ & $\begin{array}{l}\text { Data of the BVDV control program (GD } \\
\text { Animal Health); expert opinion }\end{array}$ \\
\hline Between herd prevalence based on young stock in all Dutch dairy herds & $\begin{array}{l}\bullet \text { 2008: } 19.4 \% \text { (95\% CI: } 16-24 \%) \\
\bullet \text { 2010: } 19.6 \% \text { (95\% CI: } 15-25 \%) \\
\bullet \text { 2012: } 12.5 \% \text { (95\% CI: } 9-17 \%) \\
\bullet 2014: 13.3 \% \text { (95\% CI: } 9-19 \%)\end{array}$ & $\begin{array}{l}\text { Bartels et al., 2008; Brouwer-Middelesch et } \\
\text { al., 2010, 2012; Veldhuis et al., } 2014\end{array}$ \\
\hline Average time in the infectious state & $\begin{array}{l}\text { Certified BVDV-free status: } 4 \text { mo; herds with a known } \\
\text { BVDV status } 12 \text { mo; herds with an unknown status } \\
41 \text { mo }\end{array}$ & $\begin{array}{l}\text { Data of the BVDV control program (GD } \\
\text { Animal Health); expert opinion; Viet et } \\
\text { al., } 2004\end{array}$ \\
\hline Time in the recovered status & Depending on the replacement rate (average $26 \mathrm{mo}$ ) & $\begin{array}{l}\text { Census data of the identification and } \\
\text { registration system }\end{array}$ \\
\hline Percentage of farms vaccinating & $\begin{array}{l}\text { @Risk Pert }(10 \% ; 15 \% ; 20 \%) \text { in } 2009 \text {; absolute } \\
\text { increase of } 1 \% \text { per year until maximum } 25 \% \text { of the } \\
\text { herds }\end{array}$ & $\begin{array}{l}\text { Personal communication, pharmaceutical } \\
\text { industry }\end{array}$ \\
\hline $\begin{array}{l}\text { Percentage of herds that are participating in the voluntary BVDV } \\
\text { control program and are certified BVDV free }\end{array}$ & $\begin{array}{l}15 \% \text { in } 2008 \text {; absolute increase in percentage of } 2 \% \text { per } \\
\text { year until maximum } 35 \% \text { of the herds. }\end{array}$ & $\begin{array}{l}\text { Data of the BVDV control program } \\
\text { (GD Animal Health), the maximum was } \\
\text { assumed after expert consultation }\end{array}$ \\
\hline $\begin{array}{l}\text { Percentage of herds with an indication of virus transmission when } \\
\text { starting to participate in the BVDV control program }\end{array}$ & $6 \%$ among cows; $22 \%$ among young stock & $\begin{array}{l}\text { Data of the BVDV control program (GD } \\
\text { Animal Health) }\end{array}$ \\
\hline $\begin{array}{l}\text { Number of PI animals detected in herds in which an indication of virus } \\
\text { circulation is present }\end{array}$ & $@$ Risk Pert $(1 ; 1 ; 8)$ & $\begin{array}{l}\text { Data of the BVDV control program (GD } \\
\text { Animal Health) }\end{array}$ \\
\hline Replacement costs PI & $\begin{array}{l}\text { Varying between } € 295 \text { (calf) and } € 560 \text { (cow) } \\
\text { depending on the age at replacement, value of live } \\
\text { cattle, and value at slaughter }\end{array}$ & KWIN, 2010 \\
\hline Herd size & 82 cows $(>2$ yr) in 2008 ; increase of 3 cows $/ y r$ & $\begin{array}{l}\text { Census data of the identification and } \\
\text { registration system; increase based on } \\
\text { increase observed in the field between } 2008 \\
\text { and } 2014\end{array}$ \\
\hline Losses per cow related to a BVDV outbreak & $\begin{array}{l}\text { @Risk Pert }(€ 19 ; € 72 ; € 387) / \text { cow indexed with } 2.5 \% / \\
\text { yr between } 2004 \text { and } 2014\end{array}$ & Hogeveen et al., 2003 \\
\hline Costs of vaccination & $@$ Risk Pert (€5; €8; €10) & Estimation after consulting multiple \\
\hline
\end{tabular}

yr between 2004 and 2014

- Consulting costs: €30 visit costs and additional costs of $€ 140 / \mathrm{h}$ (time for sampling estimated at $2 \mathrm{~min} / \mathrm{cow}$ ) - Material costs $€ 0.45 /$ cow

- Ear-notch samples €9.40

- Serum: ELISA €11.20/cow; €7.45/cow in pool. PCR $€ 13.20$

- Bulk milk (BTM): ELISA €28.50/sample. PCR

$€ 91.80$ /sample

- Participation in the BVDV control program €111/yr

- Quick screening of herd based on BTM and 5 young stock 8-12 mo €137.25

Estimation after consulting multiple veterinary practices

Estimation after consulting multiple veterinary practices

Actual tariff information of GD Animal Health in 2014. Available at www. gdanimalhealth.com 
Table A2. Description and assumptions included for each of the 4 included bovine viral diarrhea virus (BVDV) control scenarios for Dutch dairy herds

Scenario $^{1} \quad$ Description

Sc1 - Exemption from taking additional actions for dairy farms that already participate in the voluntary BVDV control program.

- In the first year, all herds are obliged to define the BVDV status of their herds based on young stock and bulk tank milk

(BTM) testing (costs: €208/herd, including testing and sampling costs).

- Subsequently, all herds are obliged to participate in a national BVDV control program. As part of this program, herds with an indication of virus circulation are obliged to trace (testing of all cattle and calves that are prospectively born within 10 mo; costs depending on herd size and test results, average $€ 2.147$ when no persistently infected (PI) animals are detected) and cull PI cattle (costs per herd highly depending on number of PI cattle and their age; replacements costs on average $€ 430$ /animal, based on Dutch bio-economic figures). Herds without indication of virus circulation or herds where all PI are removed receive an official BVDV-free status.

- The free status is monitored biannually based on serological testing of 5 calves between 8 and 12 mo of age (costs: €330/ herd per year, including costs of participation in the BVDV control program, which covers the testing costs and sampling costs). Based on these actions, PI calves are assumed to remain undetected in the herd for a maximum of 6 mo.

- When herds purchase cattle from herds with a lower BVDV status, the purchased cow has to be tested (total costs: €58).

- It is assumed that in this scenario $33 \%$ of all dairy farmers will implement vaccination in their herd (total additional costs: $@$ Risk Pert $€ 5 ; € 8 ; € 10$ per vaccination/cow). Effectiveness of the vaccine is assumed $99.9 \%$, and $90 \%$ of the farmers are assumed to vaccinate according to the manufactures' instructions.

Sc2 All herds are obliged to implement vaccination within their herds resulting in all cattle to be vaccinated twice a year (total costs: @Risk Pert €5; €8; €10 per vaccination/cow).

- In the first year of vaccination, cows receive an extra primer vaccination.

- Effectiveness of the vaccine is assumed as $99.9 \%$, and $90 \%$ of the farmers are assumed to vaccinate according to the manufacturers' instructions.

- The voluntary BVDV program will stop existing.

- No additional actions are taken to trace and cull PI cattle.

- Exemption from taking additional actions for dairy farms that already participate in the voluntary BVDV control program.

- In the first year, all herds are obliged to define the BVDV status of their herds based on young stock and BTM testing

(costs: €208/herd, including testing and sampling costs).

- Herds with an indication of virus circulation are obliged to trace (testing of all cattle and calves that are prospectively born within 10 mo, costs depending on herd size and test results, average €2.147 when no PI are detected) and cull PI cattle (costs per herd highly depending on number of PI cattle and their age (replacements costs on average €430/animal).

- All herds that are not officially certified BVDV-free will test all newborn calves based on ear-notch samples (average costs: $€ 13.40$ /sample) for a 3-yr period.

- After 3 yr, the monitoring will change into biannual serologic testing in 5 calves between 8 and 12 mo of age (costs: €330/ herd/yr, including costs of participation in the BVDV control program, which covers the testing costs and sampling costs).

- Herds in which a new infection occurs are obliged to trace and cull PI as mentioned above.

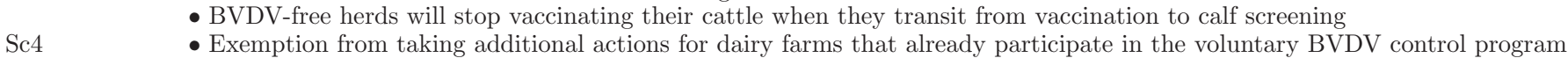

- All herds are obliged to define the BVDV status of their herds based on young stock and BTM testing (costs: €208/herd, including testing and sampling costs).

- It is assumed that 50\% of the herds with an indication of virus circulation will trace (testing of all cattle and calves that are prospectively born within 10 mo; costs depending on herd size and test results, average $€ 2.147$ when no PI are detected) and cull PI cattle on a voluntary basis (costs per herd highly depending on number of PI cattle and their age; replacement costs on average $€ 430 /$ animal). It is assumed that $25 \%$ of herds with high levels of antibodies but with no direct indication of PI will aim at becoming officially BVDV free. In addition, it is assumed that $75 \%$ of farms without indications of BVDV circulation will take additional measures. All other herds are assumed to take no additional measures until they become obligatory.

- Herds that are declared BVDV free in the program will biannually monitor their free status based on serological testing of 5 calves between 8 and 12 mo of age (costs: $€ 330$ /herd per year, including costs of participation in the BVDV control program, which covers the testing costs and sampling costs). Based on these actions, PI calves are assumed to remain undetected in the herd for a maximum of 6 mo.

- When control actions become obligatory, all herds without an official free status have to trace and cull PI cattle and all herds have to monitor their subsequent free status.

- When herds purchase cattle from herds with a lower BVDV status during the voluntary period, the purchased cow has to be tested. When control measures become obligatory, herds without official BVDV-free statuses are prohibited from selling their cattle to other dairy farms.

- It is assumed that $19 \%$ (minimum 14\%; maximum 24\%) of the farmers will vaccinate their cattle throughout the study period (average $€ 16 /$ cow per year without primer vaccination).

${ }^{1}$ Sc1: obligatory tracing and removing PI animals and monitoring of the subsequent status while vaccination for BVDV is allowed. Sc2: vaccination for BVDV is obligatory in all Dutch dairy herds. Sc3: obligatory tracing and removing of PI animals and monitoring of the subsequent status based on ear-notch sampling of newborn calves. Sc4: determining the BVDV status followed by control measures on a voluntary basis for 3 yr. After this period, obligatory tracing and removing of PI animals and monitoring of the BVDV-free status in which vaccination is allowed. ${ }^{2} @$ Risk (Palisade Corporation, Ithaca, NY). 